\title{
USING INSOMNIA AS AN EXPLANATORY MECHANISM BETWEEN JOB INSECURITY AND INTERPERSONAL CONFLICT, WITH THE MODERATING EFFECT OF NEUROTICISM
}

\author{
AMINA TARIQ \\ Capital University of Science and Technology, Islamabad, Pakistan
}

\begin{abstract}
Purpose of this research study was to investigate the impact of job insecurity on interpersonal conflict. The study also explores the mediating role of insomnia and moderating role of neuroticism. The survey was conducted on female workers of different organizations located in Pakistan and Azad Jammu and Kashmir. Data were collected using questionnaire from 285 female workers. Results suggested that job insecurity is positively associated with interpersonal conflict, and insomnia plays its role as a mediator between job insecurity and interpersonal conflict; whereas, neuroticism moderates the relationship of insomnia and interpersonal conflict. The study concludes with some implications and provides directions for the future research.
\end{abstract}

\section{INTRODUCTION}

Work is a central a part of life to many human beings - it fulfils each monetary and social needs. Jobs provide individuals with income, social contacts, possibilities of personal development, as well as daily structure. Previous literature suggests that the nature of work is changing at a quicker pace even for employees who are hired or have survived organizational alternate (Fatimah et al., 2012). Changes in the economic, political and social circles have forced the worldwide organizations to deal with an extensive range of adaptive strategies in order to maintain competitiveness in an increasingly supple labour market (Sverke et al., 2002). Organizations are engaged in the adaptive strategies such as downsizing, right sizing or restructuring (Mauno \& Kinnunen, 2002), which are highly characterized in the current working conditions, organizations, in an attempt to survive in difficult economic conditions, are using one of these adaptive strategies. Most current research on job insecurity focuses mainly on its adverse consequences on people as well as on companies (Greenhalgh \& Rosenblatt, 1984).

From existing literature, it is examined that job insecurity is basically placed among employment and unemployment, because it typically refers to employed individuals who are concerned about unemployment (De Witte, 2005). Greenhalgh and Rosenblatt (1984) define job insecurity as "the perceived powerlessness to hold the preferred continuity in a threatened job situation". It is the chance of job loss or job discontinuity (De Witte, 1999).
It is most often characterized by phenomena including anxiety and depression (Dekker \& Schaufeli, 1995). Additionally, strain-related psychosomatic complaints are suggested as an outcome of job insecurity (Cheng \& Chan, 2008). Job insecurity displays the perceived tension about dropping one's task. The situation, often is such that people experiencing job insecurity also generally tend to react to the dissatisfying occasions in ways that have an effect on the organization as well (Sverke et al., 2002).

The main purpose of the study is to broaden and deepen current understanding of the relationship between job insecurity and interpersonal conflict, along with the mediating role of insomnia and moderating role of neuroticism in the organizations of Pakistan. The previous research has shown that conduct of individuals varies throughout cultures and people behave differently in similar situations because of differences in lifestyle (Hofstede, 1983). The study aims to figure out the effect of job insecurity on interpersonal conflict of the female employees working in distinctive organizations. Pakistan is still a growing nation and the percentage of female workers working within the companies is growing by the day; however, the female employees experience job insecurity and fear of losing job as compared to their male counterparts. Therefore, the present study will assist the organizations in Pakistan to understand the fact that how job insecurity results in interpersonal conflict between the personnel in the organization. Going about this course in the study through insomnia as a mediator and neuroticism as moderator, it will have certain 
implications within the current literature, theoretically and practically.

Job insecurity is believed to lead to interpersonal conflict, both being counterproductive organizational behavior. As per Social Exchange Theory (Homans, 1961), when an individual at work faces unfavourable situation, he/she reacts in deleterious manner, accordingly. Therefore, when an employee experiences job insecurity, it leads to interpersonal conflict, due to the fear of losing job and at times, inability to do anything substantial about it. Social exchange theory has been offered as a possible avenue for studying the components of employee relationship. This theory attempts to explain interpersonal relationships in terms of transactions of resources governed by the principle of repayment in kind with the actions of one party often dependent on those of the other (Blau, 1964). When employees perceive insecurity at job they feel stressed and in exchange they react and initiate revenge seeking or coping strategies by showing negative behaviors at workplace which leads toward the conflict between the employees.

\section{LITERATURE REVIEW}

\section{Job Insecurity and Interpersonal Conflict}

The term conflict is basically an interactive manner that is contemplated inside the social entities such as individual, groups or organization, in the form of incompatibility, disagreement or variations. Conflict takes place while an individual is needed to have interaction in the activity which is unique with his or her interest (Jehn \& Mannix, 2001). It also happens when an individual holds behavioral choices and then he/she discovers that his/her preferences are incompatible, that's applied by way of every other person. Conflict has been employed in one of a kind ways demonstrating different ranges in which the conflict exists (Deutsch, 1990). Conflict at the workplace is considered as common workplace stressor. Basically, conflict at workplace, such as interpersonal conflict, shows a degree of reaction in which an employee behaves negatively to the social interaction with his/her co-workers. Wall and Callister (1995) define interpersonal conflict as "a process in which one party perceives that its interests are being opposed or negatively affected by another party". The previous literature suggests that interpersonal conflict has also been related to the negative emotions and poor psychological states such as anxiety, anger and frustration (Liu, Spector, \& Shi, 2007).

In the latest literature, there may be evidence that dropping one's job has unfavourable effects on health, which may fit in such a way which induces a greater threat of mortality. Despite the fact that job loss has been considered as a traumatizing event, it is far likely not very common. In assessment, the threat of job loss, such as perception of job insecurity, is probably more extensive and one might also marvel its effects as negative as that of actual job loss. Additionally, modernday financial and economic conditions are a component that is considered vital to discover how personnel are suffering from the growth in call for the flexibility within the work situations (Østhus, 2007). The previous literature counselled that once personnel experience job insecurity, they go through a large number of negative outcomes, which might also negatively affect the organization. From the literature, it has been found that job insecurity is negatively related to job satisfaction, trust, job performance, job commitment and it has been additionally associated with psychological and physical health outcomes (Sverke et al., 2002).

The impact of job insecurity on interpersonal conflict is understood by frustration and aggression theory (Dollarde et al., 1939). Frustration and aggression theory provides the model which proposed that frustration causes aggression, because of which negative outcomes are generated. It is found that in the face of adverse situations at workplace, employees become frustrated and this frustration leads to the aggression. The frustration-aggression hypothesis (Dollarde et al., 1939) shows that frustration takes place when activities interfere with one's goals and the basic response to frustration is aggression, which ultimately, gives rise to interpersonal conflict.

The growing body of literature suggested that feelings of job insecurity within the time of transformation in the agency has undoubtedly associated with the job burnout (Mauno \& Kinnunen, 2002), poor communication among the employees inside the organization (De Witte, 2005), and one-of-a-kind forms of conflict within the organization (Hoel \& Cooper, 2000). People are in the state of conflict while they may be irritated by way of other person's and unavoidably respond to it in a costly manner (Van de Vliert, 1997).

Hence, as per literature reviewed, the following hypothesis is developed:

$$
\begin{aligned}
& \text { Hypothesis 1. Job insecurity is positively } \\
& \text { associated with interpersonal conflict. }
\end{aligned}
$$

\section{Insomnia as a mediator between job insecurity and interpersonal conflict}

Human life is filled with the events that affect the occasional insomnia in a person who typically sleeps properly. However, a large number of people have been 
suffering from this situation repetitively, but sometimes, the situation prolongs for an extended period that could remain from some months to several years. Insomnia has been characterized with the aid of delayed sleep disorder, sustained awakenings at some stage in the night time, or early morning awakening (Ford \& Kamerow, 1989). Sleep disorder such as insomnia is not unusual in women as compared to men and takes place at disproportionately high charges in older people (Mellinger, Baiter, \& Unlenhuth, 1985). The person with insomnia not only experiences poor sleep, however, normally they also complain about daytime impaired functioning. Reports of fatigue, mood sickness, sleepiness, and tension may additionally contribute (Altena et al., 2008).

Literature of epidemiology, public health and occupational psychology have shown that when individuals suffer from the fear of job insecurity it is perilous for the fitness of individual and it is the main cause of increase in the strain and stress (Sverke \& Hellgren, 2002). Psychologists are of the view that predication of some occasion and worrying on that is more crucial and it leads to severe anxiety rather than the event itself. More often than not, job insecurity gives rise to self-pronounce and widespread psychological morbidity and bad health (Ferrie, 2001). Mainly, it is significantly related to unique symptoms together with stomach, skin issues, eyestrain, and sleep issues (Cheng et al., 2005). Job insecurity is also negatively correlated with mental fitness (Ferrie et al., 2005). Ample literature posits that job insecurity is one of the leading causes of adverse effects on health of individuals.

Apart from physical and certain psychological symptoms, quality of sleep gets deteriorates due to interpersonal conflict, at workplace. Nakata et al. (2004), in their study on white- collar employees established that the employees who were facing severe intra- organisation conflict were experiencing relentless insomnia threat. Similarly, when they conducted the same study in business sector, the results showed that a large number of male employees, who were facing more interpersonal conflict at workplace, had much more risks of certain sleep disorders (Nakata et al., 2008). As a result, sleep related health troubles arise preceded by interpersonal conflict at work. Specifically, job insecurity, can contribute to autonomic arousal and emotional misery, all of which lead to extended insomnia (Bonnet \&Arand, 1997; Harvey, 2002). Job insecurity may additionally cause intrusive and traumatic mind, namely to rumination, a cognitive notion, which is characterized by means of a focus on the beyond and concerns subject matters of loss. Those repetitive minds can also intervene with people' potential to fall asleep, as has been proven in past research (Carney, Harris Moss, \&Edinger, 2010). From the above debate, it has been analyzed that job insecurity is positively associated with interpersonal conflict. So when job insecurity leads to sleep disorder among the workers, it resultantly increases interpersonal conflict.

\section{Hypothesis 2. Insomnia mediates the relationship between job insecurity and interpersonal conflict.}

\section{Neuroticism as a moderator between insomnia and interpersonal conflict}

A person's environment is believed to have a deep effect on his/her personality, character and decision making tactics. The role of personality as a moderator has been a subject of interest for years (Costa \& McCrea, 1992); although, only a handful of researchers have examined their effects within the context of the social stressor-pressure (Bono, Boles, Choose, \& Lauver, 2002). Neuroticism is a personality trait characterized by using an inclination to experiencing low moods and emotional instability (Costa \& McCrae, 1980). Neuroticism refers to a negative affect (Eysenck, 1967) and it appears in almost all classifications of different personality types. It refers to an emotional trait in which individual are inspired easily, but their ability to inhibit emotions is slow (Eysenck, 1991). According to Costa and MacCrae (1992) neuroticism refers to a dimension of emotions which are negative versus stability of emotions and their adjustment.

A few people with insomnia revel in symptoms similar to neuroticism. Therefore, it can be said that neuroticism refers to negative affectivity, depression and sort of anxiety (Watson \& Clark, 1984), it is a personality trait which is caused by genetic and environment (McRae, Jang, Livesley, Riemann, \& Angleitner, 2001). Traits are the tendencies that help people to experience the environment in a different way from others. So neuroticism leads individuals towards emotions, cognitions and behaviours which are negative (Jang, McCrae, Angleitner, Riemann, \& Livesley, 1998). So it can be said that disorders in sleep have emotion related (Dahl \& Lewin, 2002), cognition related, and behavior related additives (Perlis et al., 1997).

People scoring high on neuroticism may be more prone to workplace conflict. These findings aid the conceptualization that neuroticism will aggravates the consequences of interpersonal conflict. Studies inspecting the moderating function of neuroticism on interpersonal conflict are rare and what has been explored previously has focused on the non-works domain names. People scoring high on neuroticism had been shown to revel in accelerated stages of interpersonal conflict (Bono et al, 2002). Dijkstra et al. (2005) stated similar findings whilst analyzing the role neuroticism plays on interpersonal conflict, displaying 
that people high on neuroticism mentioned higher stages of interpersonal conflict. Additionally, Milam, Spitzmueller, and Penney (2009) confirmed that neurotic people perceived more conflict, by the virtue of the fact that those individuals may be predisposed as being demanding, nervous, insecure, prone to self-pity, which might also cause them to seek conflicting situation at the workplace.

It is normally believed that sleep problem is related to damaging situations at work, which further is related to adverse impact on workers' relationships (Kim et al., 2011). Interpersonal conflict is likewise having a bad impact on the employee's relationship; similarly, neuroticism, which is based totally on anger, anxiety, frustration, has similar impact. So the previous literature suggests that neuroticism strengthen the relationship between insomnia and interpersonal conflict. Therefore, the subsequent hypothesis is developed:

Hypothesis 3. Neuroticism moderates the relationship between insomnia and interpersonal conflict.

\section{THEORETICAL FRAMEWORK}

\section{FIGURE 1}

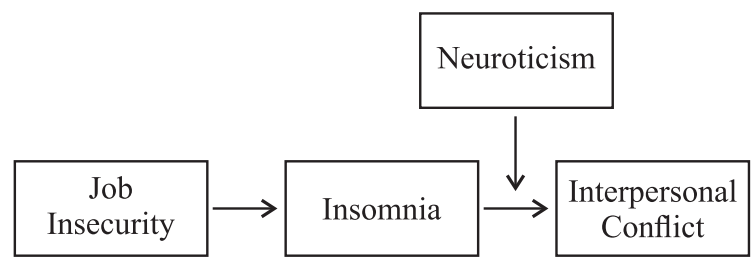

\section{METHODOLOGY}

The study undertaken focuses on the impact of job insecurity on interpersonal conflict, with the mediating role of insomnia and moderating effect of neuroticism. This is a cross sectional study with the unit of analysis as individuals. The data were collected from the female workers of different organizations in Pakistan. The sampling technique used was convenient sampling due to the time and budget constraints. Total 400 questionnaires were distributed out of which 310 were returned and only 285 were usable. Researcher's interference was minimal and the respondents were assured of the confidentiality of the data.

\section{INSTRUMENTATION}

\section{Job insecurity}

Job insecurity was measured with the 4-item Job
Insecurity Scale by Vander Elst, De Witte, and De Cuyper (2014). A sample item is 'I think I will lose my job in the near future'. The items were rated on a 5-point Likert-type scale ranging from 1 (strongly disagree) to 5 (strongly agree). The value of Cronbach's alpha was found as 0.754 which confirms the reliability and consistency of an instrument used to measure job insecurity in a current study.

\section{Insomnia}

Insomnia was assessed using the Women Health Initiatives Insomnia Scale (Levine et al., 2003). This scale consists of five items and uses a 5-point Likert-type response pattern with Cronbach's alpha at 0.784 . The items assessed ongoing difficulties with sleep. A sample item is 'Did you have trouble falling asleep'.

\section{Neuroticism}

For neuroticism, an 8-item scale of Big Five Personality Model of (John \&Srivastava, 1999) was used. A sample item is 'I dislike myself'. The items were rated on a 5-point Likert-type scale ranging from 1 (strongly disagree) to 5 (strongly agree). And the Cronbach's alpha was at 0.712 .

\section{Interpersonal conflict}

Interpersonal conflict was measured with the 5 -items of (Doucet, Poitras, \&Chênevert, 2009). A sample item is 'People often create obstacles for others'. The items were rated on a 5-point Likert-type scale ranging from 1 (strongly disagree) to 5 (strongly agree). After doing the reliability analysis, the value of Cronbach's alpha was found as 0.812 .

\section{RESULTS}

The hypotheses were tested by regression analysis the results of which are as follow:

The findings of correlation analysis, as shown in table (1) indicate that job insecurity and interpersonal conflict are positively and significantly correlated $(r=$ $\left..321^{* *}, \mathrm{p}<0.01\right)$. Similarly, a positive and significant correlation exists between job insecurity and insomnia $\left(\mathrm{r}=.188^{*}, \mathrm{p}<0.05\right)$ as well as between insomnia and interpersonal conflict $\left(\mathrm{r}=.175^{*}, \mathrm{p}<0.05\right)$. Likewise, job insecurity and neuroticism are highly correlated at $\mathrm{r}=.229^{* *}$, where $\mathrm{p}<0.01$; along with neuroticism and interpersonal conflict $\left(\mathrm{r}=.440^{* *}, \mathrm{p}<0.01\right)$. And finally, neuroticism and insomnia are also positively and significantly correlated $\left(\mathrm{r}=.134^{*}, \mathrm{p}<0.05\right)$. 
TABLE 1

Correlation Analysis

\begin{tabular}{|c|c|c|c|c|c|c|c|c|}
\hline Variables & 1 & 2 & 3 & 4 & 5 & 6 & 7 & 8 \\
\hline 1. Age & 1 & & & & & & & \\
\hline 2. Gender & .00 & 1 & & & & & & \\
\hline 3. Qualification & $.190 * *$ & .00 & 1 & & & & & \\
\hline 4. Experience & $.764 * *$ & .00 & $.340 * *$ & 1 & & & & \\
\hline 5. Job Insecurity & $-.118 *$ & .00 & -.056 & $-.230 * *$ & 1 & & & \\
\hline 6. Insomnia & -.017 & .00 & $.239 * *$ & $.144 *$ & $.188 *$ & 1 & & \\
\hline 7. Interpersonal Conflict & .075 & .00 & $\neg-.220 * *$ & .048 & $.321 * *$ & $.175^{*}$ & 1 & \\
\hline 8. Neuroticism & $.261 * *$ & .00 & .048 & $.212 * *$ & $.229 * *$ & $.440 * *$ & $.134 *$ & 1 \\
\hline
\end{tabular}

TABLE 2

Results of Regression Analysis for Outcome

\begin{tabular}{|c|c|c|c|c|c|c|}
\hline \multirow[t]{2}{*}{ Predictor } & \multicolumn{3}{|c|}{ Insomnia } & \multicolumn{3}{|c|}{ Interpersonal Conflict } \\
\hline & $\boldsymbol{\beta}$ & $\mathbf{R}^{2}$ & $\Delta \mathbf{R}^{2}$ & $\boldsymbol{\beta}$ & $\mathbf{R}^{2}$ & $\Delta \mathbf{R}^{2}$ \\
\hline \multicolumn{7}{|l|}{ Step 1} \\
\hline Control Variable & & & & & .067 & \\
\hline \multicolumn{7}{|l|}{ Step 2} \\
\hline Job Insecurity & & & & $.248 * * *$ & .187 & $.120 * * *$ \\
\hline \multicolumn{7}{|l|}{ Step 1} \\
\hline Control Variable & & & & & .067 & \\
\hline \multicolumn{7}{|l|}{ Step 2} \\
\hline Insomnia & & & & $.080 *$ & .084 & $.017 *$ \\
\hline
\end{tabular}

$N=285, * * * p \leq 0.001, \quad * * p \leq 0.01, * p \leq 0.05$.

TABLE 3

Mediated Regression Analysis

\begin{tabular}{ccccccc}
\hline Predictors & Insomnia & \multicolumn{3}{c}{ Interpersonal Conflict } \\
& $\boldsymbol{\beta}$ & $\mathbf{R}^{2}$ & $\Delta \mathbf{R}^{2}$ & $\boldsymbol{\beta}$ & $\mathbf{R}^{2}$ & $\Delta \mathbf{R}^{2}$ \\
\hline
\end{tabular}

Step 1

Control Variable

0.92

Step 2

Job Insecurity $\quad .167^{*} \quad .111 \quad .017^{*}$

Mediation Insomnia

Step1

Control variable

0.067

Step 2

Insomnia

$0.080 * \quad 0.084$

0.017

Step 3

Job Insecurity

$0.239 * * * \quad 0.193$

0.110

$N=285 ; * * * p<0.001, * * p<0.01, * p<0.05$

The first hypothesis proposed that job insecurity is positively associated with interpersonal conflict. To test that proposition job insecurity was regressed on interpersonal conflict. In step 1, all the control variables (age, gender, qualification and experience) were entered; the $\mathrm{R}^{2}$ value is .067. In step 2 , job insecurity was regressed on interpersonal conflict and the results showed that it is a significant predictor of interpersonal conflict. Consistent with the proposition job insecurity is significantly and positively related to interpersonal conflict $\left(\beta=.248^{* * *}\right.$, 
$\mathrm{p}<0.001$ ), thus supporting hypothesis $\mathrm{H}_{1}$.

Table (3) shows the results of mediation analysis. The results of mediation analysis indicate that by incorporating insomnia as a mediator, although the relationship between job insecurity and interpersonal conflict is significant $\left(\beta=0.080 *{ }^{*} p<0.05\right)$, the direct relationship between the two variables is far more significant at $\beta=0.239^{* * *}$, where $* * * p<0.001$. Therefore, the findings suggest that insomnia partially mediates the relationship between job insecurity and interpersonal conflict, thus leading to the acceptance of mediation hypothesis, i.e. hypothesis 3 .

TABLE 4

Moderated Regression Analysis

\begin{tabular}{cccc}
\hline Predictor & & \multicolumn{2}{c}{ Interpersonal Conflict } \\
& $\boldsymbol{\beta}$ & $\mathbf{R}^{\mathbf{2}}$ & $\Delta \mathbf{R}^{\mathbf{2}}$ \\
\hline
\end{tabular}

Moderation

Step 1

Control Variable

.067

Step 2

Insomnia

$.089 * * *$

Neuroticism

$.416^{* * *}$

.276

$.210 * *$

Step 3

$\begin{array}{llll}\text { Ix N } & .355^{* * *} & .466 & .190 * *\end{array}$

$N=285 ; * * * p<0.001,{ }^{* *} p<0.01, * p<0.05$.

For moderated regression analysis following steps of Barren and Kenny (1986) are followed: in the first step, age, gender, qualification and experience were entered as control variables. In second step insomnia and neuroticism were entered to predict the interpersonal conflict. Step 2 shows that insomnia is significantly associated with the interpersonal conflict $(\beta=.089 * * *, p<.001)$. In third step, interpersonal conflict was regressed on the interaction term of neuroticism and insomnia. The result shows that the relationship between insomnia and interpersonal conflict is moderated by neuroticism, i.e. it strengthens the relationship $\left(\beta=.355^{* * *}, \mathrm{p}<.001\right)$ as shown in Table 4, leading to the acceptance of hypothesis 3 .

\section{DISCUSSION AND CONCLUSION}

The aim of this study was to check the impact of job insecurity on interpersonal conflict, i.e. explore that whether job insecurity causes interpersonal conflict in the workplace or not and if it does, then what are the factors leading up to it. The results of the study indicated that there is positively significant relationship among job insecurity and interpersonal conflict; as when female employee feels insecure about her job it will lead to interpersonal aggression and conflict. Similarly, the results of the study helped establish that insomnia partially mediates the relationship between job insecurity and interpersonal conflict. The reason being that job insecurity is relatively high among female workers that employees are always working under the threat of being a victim of restructuring, policy changes and cost cutting. The results shows that when the female workers feels insecurity about their job its effects on interpersonal relationship is so much high that it can give rise to high level of conflict among employees, lead by psychological health issues, i.e. insomnia, as previously supported by literature.

Similarly, insomnia happens to cause interpersonal conflict in the workplace because both are counterproductive work behaviours; interpersonal conflict is a negative behavior and insomnia causes and increases negative behaviors in the organization, furthermore, neuroticism moderates this relationship by strengthening the impact of negative behavior. As the value of $\beta$ is highly significant it shows that neuroticism is playing the role of moderator in this specific relationship. This is also supported by prior research, which shows that neuroticism strengthens the said relationship.

\section{Limitations}

There are certain limitations in the study. Current study focuses on female workers of organizations of Pakistan and Azad Kashmir. In order to enhance the conciseness and the generalizability of the research, data from the male workers should also be collected. Furthermore, a relatively small sample size is one of the limitations. A study on bigger sample size can prove useful in order to provide a bigger picture.

\section{Implications and future directions}

The study has certain implications in the specific area of literature. It helps expand the interpersonal conflict relationship with job insecurity. In literature there is very minimal work done on the relationship among job insecurity and interpersonal conflict so it will be an addition to it. The mediating and moderating roles added in this study make it unique as the mediator insomnia is totally a new concept in the Pakistani context. As far as context is concerned, the current study can prove to be vital as there is very limited research on the topic, as far as the developing countries are concerned. The study can be highly useful in the organizational context, giving it certain practical implications. The organizations needs to know that for the growth or development or better environment there is need to provide its employees job security, which will help to create a good and 
healthy relationship between employees within the organization.

For future studies, it can be useful to consider some other mediators and moderators and test their impact on this relationship; like personality factors such as narcissism as a moderation to explore how narcissism affects this relationship and will the results be same or not. Psychological factors such as anxiety, frustration and stress can also be added as a mediator in the relationship of job insecurity and interpersonal conflict.

\section{REFERENCES}

Altena, E., Van Der Werf, Y. D., Strijers, R. L., \& Van Someren, E. J. (2008). Sleep loss affects vigilance: effects of chronic insomnia and sleep therapy. Journal of Sleep Research, 17(3), 335-343.

Blau, P. M. (1964). Exchange and power in social life. Transaction Publishers.

Bonnet, M. H., \&Arand, D. L. (1997).Hyperarousal and insomnia. Sleep medicine reviews, 1(2), 97-108.

Bono, J. E., Boles, T. L., Judge, T. A., \& Lauver, K. J. (2002). The role of personality in task and relationship conflict. Journal of Personality, 70(3), 311-344.

Carney, C. E., Harris, A. L., Moss, T. G., \& Edinger, J. D. (2010).Distinguishing rumination from worry in clinical insomnia. Behaviour Research and Therapy, 48(6), 540-546.

Cheng, G. H. L., \& Chan, D. K. S. (2008). Who suffers more from job insecurity? A meta-analytic review. Applied Psychology, 57(2), 272-303.

Cheng, Y., Chen, C. W., Chen, C. J., \& Chiang, T. L. (2005).Job insecurity and its association with health among employees in the Taiwanese general population. Social Science \& Medicine, 61(1), 4152.

Costa, P. T., \& McCrae, R. R. (1992a). Four ways five factors are basic. Personality and Individual Differences, 13(6), 653-665.

Costa, P. T., \& McCrae, R. R. (1992b). Normal personality assessment in clinical practice: The NEO Personality Inventory. Psychological Assessment, 4(1), 5-13.

Dahl, R. E., \&Lewin, D. S. (2002). Pathways to adolescent health sleep regulation and behavior. Journal of Adolescent Health, 31(6), 175-184.

De Witte, H. (1999). Job insecurity and psychological well-being: Review of the literature and exploration of some unresolved issues. European Journal of Work and Organizational Psychology, 8(2), 155-177.

De Witte, H. (2005). Job insecurity: Review of the international literature on definitions, prevalence, antecedents and consequences. SA Journal of Industrial Psychology, 31(4), 1-6.
Dekker, S. W., \& Schaufeli, W. B. (1995). The effects of job insecurity on psychological health and withdrawal: A longitudinal study. Australian Psychologist, 30(1), 57-63.

Deutsch, M. (1990). Sixty years of conflict. International Journal of Conflict Management, 1(3), 237-263.

Dijkstra, M. T., van Dierendonck, D., Evers, A., \& De Dreu, C. K. (2005). Conflict and well-being at work: the moderating role of personality. Journal of Managerial Psychology, 20(2), 87-104.

Dollard, J., Miller, N. E., Doob, L. W., Mowrer, O. H., \& Sears, R. R. (1939). Frustration and a g gression. US: Yale University Press

Doucet, O., Poitras, J., \& Chênevert, D. (2009).The impacts of leadership on workplace conflicts. International Journal of Conflict Management, 20(4), 340-354.

Eysenck, H. J. (1967). The biological basis of personality (Vol. 689).Transaction publishers.

Eysenck, H. J. (1991). Dimensions of personality: 16, 5 or 3?-Criteria for a taxonomic paradigm. Personality and Individual Differences, 12(8), 773-790.

Fatimah, O., Noraishah, D., Nasir, R. \&Khairiddin, R. (2012). Employment security as moderator on the effect of job security on worker' $s$ job satisfaction and well-being. Asian Social Science, 8(9), 50-56.

Ferrie, J. E. (2001). Is job insecurity harmful to health? Journal of the Royal Society of Medicine, 94(2), 7176.

Ferrie, J. E., Shipley, M. J., Newman, K., Stansfeld, S. A., \& Marmot, M. (2005). Self-reported job insecurity and health in the Whitehall II study: potential explanations of the relationship. Social Science \& Medicine, 60(7), 1593-1602.

Ford, D. E., \&Kamerow, D. B. (1989). Epidemiologic study of sleep disturbances and psychiatric disorders: an opportunity for prevention. Jama, 262(11), 1479-1484.

Greenhalgh, L., \& Rosenblatt, Z. (1984). Job insecurity: Toward conceptual clarity. Academy of Management Review, 9(3), 438-448.

Harvey, A. G. (2002). A cognitive model of insomnia. Behaviour Research and Therapy, 40(8), 869-893.

Heaney, C. A., Israel, B. A., \& House, J. S. (1994). Chronic job insecurity among automobile workers: Effects on job satisfaction and health. Social science \& Medicine, 38(10), 1431-1437.

Hellgren, J., \& Sverke, M. (2003). Does job insecurity lead to impaired well-being or vice versa? Estimation of cross-lagged effects using latent variable modelling. Journal of Organizational Behavior, 24(2), 215236.

Hellgren, J., \&Sverke, M., \& Isaksson, K. (1999). 'A twodimensional approach to job insecurity: Consequences for employee attitudes and well- 
being'. European JournalofWorkand Organizational Psychology, 8(2), 179-195.

Hoel, H., \& Cooper, C. L. (2000). Destructive conflict and bullying at work. Manchester: Manchester School of Management, UMIST.

Hofstede, G. (1983). The cultural relativity of organizational practices and theories. Journal of International Business Studies, 14(2), 75-89.

Homans, G. C., \& Merton, R. K. (1961). Social Behavior: Its Elementary Forms: Under the General Editorship of Robert K. Merton. Harcourt, Brace \& World.

Ilies, R., Johnson, M. D., Judge, T. A., \& Keeney, J. (2011). A within-individual study of interpersonal conflict as a work stressor: Dispositional and situational moderators. Journal of Organizational Behavior, 32(1), 44-64.

Jang, K. L., McCrae, R. R., Angleitner, A., Riemann, R., \&Livesley, W. J. (1998). Heritability of facetlevel traits in a cross-cultural twin sample: support for a hierarchical model of personality. Journal of Personality and Social Psychology, 74(6), 1556.

Jehn, K. A., \&Mannix, E. A. (2001). The dynamic nature of conflict: A longitudinal study of in tragroup conflict and group performance. Academy of Management Journal, 44(2), 238-251.

John, O. P., \& Srivastava, S. (1999). The Big Five trait taxonomy: History, measurement, and theoretical perspectives. Handbook of personality: Theory and Research, 2(1999), 102-138.

Kim, H. C., Kim, B. K., Min, K. B., Min, J. Y., Hwang, S. H., \& Park, S. G. (2011). Association between job stress and insomnia in Korean workers. Journal of Occupational Health, 53(3), 164-174.

Lavie, P. (2001). Sleep disturbances in the wake of traumatic events. New England Journal of Medicine, 345(25), 1825-1832.

Levine, D. W., Lewis, M. A., Bowen, D. J., Kripke, D. F., Kaplan, R. M., Naughton, M. J., \& Shumaker, S. A. (2003).Reliability and validity of Women's Health Initiative Insomnia Rating Scale. Psychological Assessment, 15(2), 137-148.

Liu, C., Spector, P. E., \& Shi, L. (2007). Cross-national job stress: a quantitative and qualitative study. Journal of Organizational Behavior, 28(2), 209-239.

Mauno, S., \&Kinnunen,U.(2002). Perceived job insecurity among dual-earner couples: Do its antecedents vary according to gender, economic sector and the measure used? Journal of Occupational and Organizational Psychology, 75(3), 295-314.

McRae, R. R., Jang, K. L., Livesley, W. J., Riemann, R., \&Angleitner, A. (2001). Sources of s tru cture :
Genetic, environmental, and artifactual influences on the covariation of personality traits. Journal of Personality, 69(4), 511-535.

Mellinger, G. D., Balter, M. B., \&Uhlenhuth, E. H. (1985). Insomnia and its treatment: prevalence and correlates. Archives of General Psychiatry, 42(3), 225-232.

Milam, A. C., Spitzmueller, C., \& Penney, L. M. (2009). Investigating individual differences among targets of workplace incivility. Journal of Occupational Health Psychology, 14(1), 58-69.

Nakata, A., Haratani, T., Takahashi, M., Kawakami, N., Arito, H., Kobayashi, F., \& Araki, S.(2004). Job stress, social support, and prevalence of insomnia in a population of Japanese daytime workers. Social Science \& Medicine,59(8), 1719-1730.

Østhus, S. (2007). For better or worse? Workplace changes and the health and well-being of Norwegian workers. Work, Employment \& Society, 21(4), 731-750.

Nakata, A., Takahashi, M., Haratani, T., Ikeda, T., Hojou, M., Fujioka, Y., \& Araki, S. (2008). Association of active and passive smoking with sleep disturbances and short sleep duration among japanese working population. International Journal of Behavioral Medicine, 15(2), 81-91.

Perlis, M. L., Giles, D. E., Mendelson, W. B., Bootzin, R. R., \& Wyatt, J. K. (1997). Psychophysiological insomnia: the behavioural model and a neurocognitive perspective. Journal of Sleep Research, 6(3), 179188.

Rosenblatt, Z., \& Ruvio, A. (1996). A test of a multidimensional model of job insecurity: The case of Israeli teachers. Journal of Organizational Behavior, 17, 587-605

Sverke, M., Hellgren, J., \& Näswall, K. (2002). No security: a meta-analysis and review of job insecurity and its consequences. Journal of Occupational Health Psychology, 7(3), 242-264.

Van de Vliert, E. (1997). Complex interpersonal conflict behavior: Theoretical frontiers. Psychology Press.

Vander Elst, T., De Witte, H., \& De Cuyper, N. (2014). The Job Insecurity Scale: A p s y c h o m e t r i c evaluation across five European countries. European Journal of Work and Organizational Psychology, 23(3), 364-380.

Wall, J. A., \&Callister, R. R. (1995).Conflict and its management. Journal of Management, 21(3), 515558.

Watson, D., \& Clark, L. A. (1984). Negative affectivity: the disposition to experience aversive emotional states. Psychological Bulletin, 96(3), 465-490. 